\title{
Analisis Highest and Best Use Pada Jalan Dr. Ir. H. Soekarno Nomor 440-484 (MERR) - Surabaya
}

\author{
Fahmi F.Alrizal ${ }^{1}$, Siti Choiriyah $^{2}$, Firmansyah Putra Pratama ${ }^{3}$ \\ ${ }^{1,2,3}$ Program Studi Teknik Sipil, Fakultas Teknik Sipil dan Perencanaan, Institut Teknologi Adhi Tama Surabaya \\ Email: $\underline{1}$ fahmi.alrizal@itats.ac.id, ${ }^{2}$ siti.choiriyah@itats.ac.id, ${ }^{3}$ firmanputrap@gmail.com
}

\begin{abstract}
The potential development of vacant land in Surabaya continues to increase. Especially on Jalan Dr. Ir. H. Soekarno Surabaya City number 440-448. In the land area, there are 2 apartment buildings, 1 hotel building, 1 housing estate, 45 office buildings, 6 shop houses, 43 restaurant buildings, 1 clinical laboratory building, 20 house buildings, 50 shopping buildings, 1 college building, and 4 school buildings. . So from such data, Dr. Ir. H. Soekarno Surabaya City number 440-448. So the area has the potential to attract investment. The Detailed Spatial Planning (RDTR) and Zoning Regulations UP 1 Rungkut 2014 state that the direction of development along Dr. Ir. H. Soekarno (MERR) in trade and service activities, as well as housing activities (vertical housing) also has the potential to develop. In order to find out which buildings are profitable on the land area, this is done by using the Highest and Best Use analysis. The analysis can take advantage of a vacant land or increase a property that is physically feasible, legally permitted, financially feasible, and has maximum productivity that comes from the highest increase in land value if a building is erected. Based on the results of data analysis on the legal, physical, financial, and maximum productivity aspects of the vacant land. So, it can be concluded that if a shop is built, the land value is Rp. 24,726,872 and land productivity of 126\%, whereas if an office is built, the land value is Rp. 23,013,522 and land productivity of $117 \%$. So that the shopping property is the best and highest alternative use that is suitable to be developed on the vacant land.
\end{abstract}

Keywords: Highest and Best Use, Empty Space, Property

\begin{abstract}
Abstrak
Pengembangan potensi penggunaan lahan yang kosong di Surabaya terus meningkat. Khususnya di Jalan Dr.Ir.H.Soekarno Kota Surabaya nomor 440-448. Di kawasan lahan tersebut terdapat 2 bangunan apartemen, 1 bangunan hotel, 1 perumahan, 45 bangunan perkantoran, 6 bangunan ruko, 43 bangunan restoran, 1 bangunan laboratorium klinik, 20 bangunan rumah, 50 bangunan pertokoan, 1 bangunan perguruan tinggi, dan 4 bangunan sekolah. Sehingga dari data yang sedemikian Jalan Dr. Ir. H. Soekarno Kota Surabaya nomor 440-448. Sehingga di kawasan tersebut memiliki potensi untuk menarik investasi. Rencana Detail Tata Ruang (RDTR) dan Peraturan Zonasi UP 1 Rungkut 2014 menyatakan bahwa arah pengembangan pada sepanjang jalan Dr.Ir.H.Soekarno (MERR) pada kegiatan perdagangan dan jasa, serta kegiatan perumahan (hunian vertikal) juga berpotensi berkembang, Agar dapat mengetahui bangunan yang menguntungkan pada lahan area tersebut dilakukan dengan menggunakan analisa Highest and Best Use. Analisa tersebut dapat memanfaatkan dari sebuah lahan kosong atau meningkatkan suatu properti yang memungkinkan secara fisik, diizinkan secara legal, finansial yang layak, dan mempunyai produktivitas maksimum yang berasal dari kenaikan nilai lahan yang tertinggi jika didirikan suatu bangunan. Berdasarkan hasil analisis dataterhadap aspek legal, fisik, finansial, dan produktivitas maksimum pada lahan kosong tersebut. Maka, dapat disimpulkan bahwa bila dibangun pertokoan memberikan nilai lahan sebesar Rp. 24.726 .872 dan produktivitas lahan sebesar $126 \%$, sedangkan bila dibangun perkantoran memberikan nilai lahan sebesar Rp. 23.013.522 dan produktivitas lahan sebesar $117 \%$. Sehingga properti pertokoan merupakan alternatif penggunaan terbaik dan tertinggi yang cocok untuk dikembangkan pada lahan kosong tersebut.
\end{abstract}

Keywords: Highest and Best Use, Lahan Kosong, Properti

\section{Pendahuluan}

Berdasarkan data Dispendukcapil Kota Surabaya tercatat bahwa jumlah warga penduduk Kecamatan Rungkut sebanyak 117.604 jiwa per bulan Januari 2020. Sehingga terdapat peningkatan 
jumlah kebutuhan dan permintaan dibidang bisnis properti, seperti apartemen, perkantoran, restoran, hotel, perumahan, dan pertokoan. Jalan Dr. Ir. H. Soekarno Kota Surabaya nomor 440-448 merupakan jalan yang memiliki lahan kosong dengan luasan $\pm 23.284 \mathrm{~m}^{2}$ sehingga menjadi salah satu kawasan yang tepat dijadikan pengembangan bisnis properti. Hal ini dikarenakan letak lokasinya yang strategis karena terdapat 2 bangunan apartemen, 1 bangunan hotel, 1 perumahan, 45 bangunan perkantoran, 6 bangunan ruko, 43 bangunan restoran, 1 bangunan laboratorium klinik, 20 bangunan rumah, 50 bangunan pertokoan, 1 bangunan perguruan tinggi, dan 4 bangunan sekolah[6],[7]. Sehingga dari data yang sedemikian Jalan Dr. Ir. H. Soekarno Kota Surabaya nomor 440-448 memiliki potensi untuk menarik investasi.[2]

Analisis tersebut memanfaatkan dari sebuah tanah kosong atau meningkatkan suatu properti yang memungkinkan secara fisik, diizinkan secara legal, finansial yang layak, dan mempunyai produktivitas maksimum yang berasal dari kenaikan nilai lahan yang tertinggi jika didirikan suatu bangunan. [2]

\section{Metode}

Pada metode penelitian ini langkah awal yang dilakukan adalah mengidentifikasikan masalah. Adapun masalah yang diangkat pada penelitian ini merupakan analisis HBU untuk mendapatkan peruntukan bangunan yang sesuai dan menguntungkan menggunakan metode HBU. Selain itu permasalahan kedua yang diangkat penulis adalah properti yang dapat memberikan penggunaan terbaik dan produktivitas lahan tertinggi dengan menggunakan analisis Highest and Best Use pada lahan kosong dengan luas $\pm 23.284 \mathrm{~m} 2$ di jalan Dr. Ir. H. Soekarno (MERR). Setelah melakukan identifikasi masalah dilakukan studi literatur untuk mendapatkan informasi mengenai analisis highest and best use.

Data yang digunakan yaitu data primer dan sekunder. Data primer pada penelitian ini didapat dari observasi lapangan, selain itu data sekunder yang didapatkan dari Dinas Tata Kota Surabaya, Peraturan-Peraturan Bangunan, PLN, PDAM, dan HSPK Kota Surabaya. Pada tahapan analisis data digunakan metode High and Best Use dengan variabel Adapun penelitian ini adalah untuk mendapatkan jenis properti komersial yang memungkinkan secara fisik, diizinkan secara legal, finansial yang layak, dan mempunyai produktivitas maksimum yang dapat memberikan nilai lahan yang tertinggi dan terbaik. $[1],[5],[12]$.

\section{Hasil dan Pembahasan}

\section{- Penentuan Alternatif}

Penentuan alternatif dilakukan secara observasi di lapangan meliputi jumlah dan jenis properti yang akan dibangun di sekitar area tersebut dan dilakukan kombinasi dengan Rencana Detail Tata Ruang(RDTR) dan peraturan Zonasi UP 1 Rungkut. Dari hasil observasi lapangan, skor tertinggi yang dianalisis adalah pertokoan, perkantoran, dan restoran. Ketiga alternatif tersebut akan dilakukan analisis berikutnya pada kelayakan aspek terhadap fisik, legal, finansial, dan produktivitas maksimal [1],[2].

\section{- Aspek Legal}

Pada analisis aspek legal dilakukan untuk mengetahui batasan maupun kapasitas maksimum pada area lahan secara hukum. Terdapat dua bagian yang ditinjau dari aspek legal, yaitu zoning dan building code. Lahan objek pada penelitian ini masuk kedalam zona jasa dan perdagangan yang dimana pada masing-masing properti mempunyai peraturan yang berbeda-beda. Berdasarkan Rencana DTRKSUP I Rungkut yang berlaku di Jalan Ir. Soekarno (MERR)[6],[7]. Hasil analisis aspek legal ditabelkan pada Tabel 1. 
Tabel 1. Hasil Analisis Aspek Legal

\begin{tabular}{cccc}
\hline & & Properti & \\
\cline { 2 - 4 } Persyaratan & Pertokoan & Perkantoran & sestoran \\
\hline $\begin{array}{c}\text { Garis Sempadan } \\
\text { Bangunan (GSB) } \\
\text { Koefisien Dasar }\end{array}$ & $\begin{array}{c}\text { sisi bangunan } \\
\text { Bangunan (KDB) } \\
\text { Koefisien Lantai }\end{array}$ & 5 meter & 5 meter \\
$\begin{array}{c}\text { Bangunan (KLB) } \\
\text { Koefisien Dasar } \\
\text { Hijau (KDH) }\end{array}$ & $60 \%$ & $60 \%$ & $50 \%$ \\
$\begin{array}{c}\text { Tinggi Maksimum } \\
\text { Bangunan }\end{array}$ & 1,8 & 3 & 2 \\
\hline
\end{tabular}

\section{- $\quad$ Aspek Fisik}

Terdapat beberapa indikator yang dapat dianalisis dari saspek fisik, diantaranya adalah ukuran lahan, lokasi lahan, aksesibilitas, dan utilitas lahan.

1. Ukuran lahan

Lahan area memiliki luas sebesar $23.284 \mathrm{~m} 2$ dan memiliki bentuk yang beraturan.

2. Lokasi Lahan

Lokasi lahan di ruas jalan MERR merupakan salah satu jalan arteri non-tol bisa disebut juga jalan nasional yang dapat dilihat pada gambar 3.2 dan memiliki letak yang strategis, dan mempunyai potensi untuk menarik investasi. Hal ini didukung dengan adanya bangunanbangunan yang terletak di area tersebut, yang diantaranya terdapat 2 bangunan apartemen, 1 bangunan hotel, 6 bangunan ruko, 45 bangunan perkantoran, 43 bangunan restauran, 1 bangunan laboratorium klinik, 50 bangunan pertokoan, 20 bangunan rumah, 3 perumahan, 1 bangunan perguruan tinggi, dan 4 bangunan sekolahan.

3. Aksesibilitas Lahan

Aksesabilitas lahan memiliki aksesabilitas yang baik karena lahan tersebut berada di jalan arteri non-tol atau jalan nasional yang cukup ramai dan menjadi akses perjalanan sarana angkutan umum.

4. Utilitas Lahan

Utilitas pada lahan ini memiliki ketersediaan yang baik mulai dari utilitas jaringan air bersih, utilitas listrik, dan utilitas jaringan telepon. Hal ini dikarenakan disekitar lahan area terdapat beberapa restoran dan perkantoran yang telah dibangun

Berdasarkan indikator aspek fisik yang meliputi, luasan lahan, aksesibilitas, dan utilitas dapat disimpulkan bahwa lahan tersebut layak secara aspek fisik karena cukup terpenuhi[7].

\section{- Perencanaan Bangunan}

Perencanaan bangunan untuk masing-masing properti akan dibangun dan direncanakan secara tata letak berdasar kombinasi peneliti dengan properti sejenis yang ada disekitarnya dan analisis aspek legal serta aspek fisik[7]. Sedangkan, untuk jumlah unit dan jumlah lantai didasarkan atas keinginan peneliti, dan berdasarkan atas RDTR UP 1 Rungkut halaman VIII-121 s/d VIII-123 untuk jumlah bangunan pada pertokoan, perkantoran, dan restoran tidak ada persyaratan dikarenakan bangunan tersebut berada pada zona perdagangan dan jasa, sehingga termasuk pemanfaatan yang diizinkan dan didapatkan hasil sebagai berikut:

1. Pertokoan 3 lantai, total 46 unit, luas perunit $15 \times 20 \mathrm{~m} 2$, total luas dasar bangunan 13.800 $\mathrm{m} 2$, total luas lantai bangunan $41.400 \mathrm{~m} 2$.

2. Perkantoran 3 lantai, total 69 unit, luas perunit $10 \times 20 \mathrm{~m} 2$, total luas dasar bangunan 13.800 $\mathrm{m} 2$, total luas lantai bangunan $41.400 \mathrm{~m} 2$.

3. Restoran 3 lantai, total 9 unit, luas perunit $16 \times 80 \mathrm{~m} 2$, total luas dasar bangunan $11.520 \mathrm{~m} 2$, total luas lantai bangunan $34.560 \mathrm{~m} 2$. 


\section{- Perencanaan Aspek Finansial}

Perencnaan aspek finansial meliputi biaya investasi, pengeluaran, penghasilan dan arus kas yang mengacu pada peraturan kota Surabaya [8],[9],[10],[11].

1. Biaya Investasi

Biaya investasi meliputi dari biaya bangunan dan tanah. Biaya tanah berdasarkan hasil perkalian luas lahan dengan harga tanah per-meter persegi. Dari perkalian tersebut didapatkan harga tanah sebesar Rp. 19.688.143,115/m2 dan nilai ini dapat diasumsikan sebagai harga tanah di sekitar Jalan Dr. Ir. H. Soekarno (MERR). Sedangkan harga biaya bangunan didapatkan dari harga dasar per-meter persegi. Pada bangunan gedung, didesain berupa gedung dengan harga minimal per-meter persegi sebesar Rp. 5.256.181 mengacu Analisa Standar Biaya kota Surabaya 2019. Perhitungan biaya investasi ditabelkan Pada Tabel 2.

Tabel 2. Hasil Analisis Aspek Legal

\begin{tabular}{cc}
\hline Jenis Bangunan & Jumlah Biaya Investasi \\
\hline Pertokoan & $\mathrm{Rp} \mathrm{702.137.324.892}$ \\
Perkantoran & $\mathrm{Rp} \mathrm{702.137.324.892}$ \\
Restoran & $\mathrm{Rp} \mathrm{661.870.773.487}$ \\
\hline
\end{tabular}

2. Biaya Pendapatan

Biaya pendapatan tiap bangunan dapat direncanakan dari penjualan, penyewaan, maintenance, dan parkir. Hasil perhitungan biaya pendapatan ditabelkan pada Tabel 3.

Tabel 3. Hasil Biaya Pendapatan

\begin{tabular}{|c|c|c|c|}
\hline \multirow{2}{*}{ Tahun } & \multicolumn{3}{|c|}{ Properti } \\
\hline & Pertokoan/Pertahun & Pertokoan/Pertahun & Perkantoran/Pertahun \\
\hline 2021 & Rp 248.918.391.137 & Rp 249.892.211.830 & Rp 37.401.770.650 \\
\hline 2022 & Rp 248.918.391.137 & Rp 249.892.211.830 & $\operatorname{Rp} 37.401 .770 .650$ \\
\hline 2023 & Rp 248.918.391.137 & $\operatorname{Rp} 249.892 .211 .830$ & Rp 37.401.770.650 \\
\hline 2024 & Rp 248.918.391.137 & $\mathrm{Rp} 249.892 .211 .830$ & Rp 37.401.770.650 \\
\hline 2025 & Rp 248.918.391.137 & $\mathrm{Rp} 249.892 .211 .830$ & $\operatorname{Rp} 37.401 .770 .650$ \\
\hline 2026 & Rp 265.081.923.029 & Rp 268.000.343.122 & Rp 49.869.027.533 \\
\hline 2027 & Rp 265.081.923.029 & $\operatorname{Rp} 268.000 .343 .122$ & Rp 49.869.027.533 \\
\hline 2028 & Rp 265.081.923.029 & Rp 268.000.343.122 & Rp 49.869.027.533 \\
\hline 2029 & Rp 265.081.923.029 & Rp 268.000.343.122 & Rp 49.869.027.533 \\
\hline 2030 & Rp 265.081.923.029 & $\operatorname{Rp} 268.000 .343 .122$ & $\mathrm{Rp} 49.869 .027 .533$ \\
\hline
\end{tabular}

3. Biaya Pengeluaran

Biaya pengeluaran dapat direncanakan mulai dari biaya operasional, biaya pajak bumi bangunan biaya pemeliharaan, dan biaya izin mendirikan bangunan. Hasil perhitungan biaya pengeluaran ditabelkan pada Tabel 4.

Tabel 4. Hasil Biaya Pengeluaran

\begin{tabular}{|c|c|c|c|}
\hline Tahun & Pertokoan/Tahun & $\begin{array}{c}\text { Properti } \\
\text { Perkantoran/Tahun }\end{array}$ & Restoran/Tahun \\
\hline 2021 & Rp 144.468.485.778 & Rp 149.667.432.422 & Rp 34.220.125.663 \\
\hline 2022 & $\mathrm{Rp} 148.160 .182 .100$ & Rp 153.506.388.923 & Rp 34.842.221.916 \\
\hline 2023 & $\mathrm{Rp} 152.081 .313 .670$ & Rp 157.575.816.434 & Rp 35.498.686.717 \\
\hline 2024 & Rp 156.258.281.603 & Rp 161.902.235.255 & Rp 36.193.474.854 \\
\hline 2025 & Rp 160.720 .524 .988 & Rp 166.515.217.376 & Rp 36.930.996.194 \\
\hline 2026 & Rp 165.902.714.168 & Rp 171.898.196.317 & Rp 38.025.167.469 \\
\hline 2027 & Rp 171.037.765.759 & Rp 177.187.023.969 & Rp 38.863.472.978 \\
\hline 2028 & Rp 176.568.339.488 & Rp 182.873.159.304 & Rp 39.761.026.234 \\
\hline 2029 & $\operatorname{Rp} 182.539 .948 .089$ & $\mathrm{Rp} 189.002 .320 .518$ & $\operatorname{Rp} 40.724 .644 .875$ \\
\hline 2030 & Rp 189.003.341.445 & Rp 195.625.486.600 & $\operatorname{Rp} 41.761 .931 .044$ \\
\hline
\end{tabular}

4. Analisis Arus Kas

Untuk analisa arus kas digunakan metode NPV (Net Present Value) yang dilakukandengan selisih pendapatan dengan pengeluaran setiap tahun dalam masa investasi untuk didapatkan aliran 
Attactive Rate of Return) maka dapat dilakukan cara menambahkan nilai dari safe rate atau nilai suku bunga bank dengan faktor resiko. Nilai dari bunga didapatkan dari rerata nilai suku bunga deposito bank di Indonesia sebesar 9,284\%. Investasi yang dikatakan layak jika ditunjukkan dengan nilai NPV positif, sedangkan investasi yang tidak layak yaitu berkebalikan yaitu NPV negatif. Perhitungan hasil analisis aspek secara finansial ditabelkan pada Tabel 5.

Tabel 5. Hasil Analisis Aspek Finansial

\begin{tabular}{cccc}
\hline \multirow{2}{*}{ Uraian } & Pertokoan & Pertokoan & Perkantoran \\
\cline { 2 - 4 } & Rp 702.137.324.892 & Rp 702.137.324.892 & Rp 661.870.773.487 \\
\hline Investasi & Rp 248.918.391.137 & Rp 249.892.211.830 & Rp 37.401.770.650 \\
\hline Pendapatan & Rp 144.468.485.778 & Rp 149.667.432.422 & Rp 34.220.125.663 \\
\hline Pengeluaran & Rp 231.482.476.786 & Rp 189.381.422.157 & - Rp 592.987.927.329 \\
\hline NPV & Layak & Layak & Tidak Layak \\
\hline Kesimpulan & &
\end{tabular}

\section{- Produktivitas Maksimum}

Dari setiap alternatif yang dinyatakan memenuhi pengujian aspek legal, fisik, dan finansial akan dianalisis pada produktivitas yang maksimal. Tujuan dari analisis produktivitas maksimum adalah untuk dicari nilai lahan dari setiap alternatif. Hasil perhitungan nilai produktivitas maksimum ditabelkan pada Tabel 6.

Tabel 6. Hasil Analisis Aspek Finansial

\begin{tabular}{ccc}
\hline \multirow{2}{*}{ Uraian } & \multicolumn{3}{c}{ Pertokoan } & Pertokoan \\
\cline { 2 - 3 } & $\mathrm{Rp} 819.459 .086 .431$ & $\mathrm{Rp} \mathrm{779.565.451.551}$ \\
\hline Nilai Properti & $\mathrm{Rp} \mathrm{243.718.600.608}$ & $\mathrm{Rp} \mathrm{243.718.600.608}$ \\
\hline Nilai Bangunan & $\mathrm{Rp} \mathrm{575.740.485.823}$ & $\mathrm{Rp} \mathrm{535.846.850.943}$ \\
\hline Nilai Lahan & $\mathrm{Rp} \mathrm{24.726.872}$ & $\mathrm{Rp} \mathrm{23.013.522}$ \\
\hline Nilai Lahan/m ${ }^{2}$ & $\mathrm{Rp} \mathrm{19.688.143}$ & $\mathrm{Rp} \mathrm{19.688.143}$ \\
\hline Nilai Lahan Awal/m $\mathrm{m}^{2}$ & $\mathbf{1 2 6 \%}$ & $\mathbf{1 1 7 \%}$ \\
\hline Produktivitas & &
\end{tabular}

\section{Kesimpulan}

Berdasarkan analisa terhadap aspek legal, fisik, finansial, dan produktivitas maksimum pada lahan kosong di jalan Dr.Ir.H. Soekarno (MERR) nomor 440-484 Kota Surabaya dengan luas $\pm 23.284 \mathrm{~m} 2$. Dapat disimpulkan bahwa bila dibangun pertokoan memberikan nilai lahan/m2 sebesar Rp. 24.726 .872 dan produktivitas sebesar $126 \%$, sedangkan alternatif bangunan perkantoran memberikan nilai lahan $/ \mathrm{m} 2$ sebesar Rp. 23.013.522 dan produktivitas sebesar 117\%. Sehingga properti pertokoan merupakan alternatif penggunaan terbaik dan tertinggi yang cocok untuk dikembangkan di lahan tersebut.

\section{Referensi}

[1] Afifuddin, A. 2009. Analisis Dampak Krisis Global Terhadap Kelayakan PLTA Pamona 2. Skripsi S1 Jurusan Manajemen

[2] Azinuddindan, M. R., dan Indryani, R. 2015. Analisa Highest and Best Use (HBU) pada Lahan Kosong Nomor 52-58 Di jalan Dinoyo Surabaya. Jurnal Teknik ITS Vol.4, No.2 : D56-D58.

[3] Mata Kuliah Manajemen Operasional (Survey pada Mahasiswa Jurusan Manajemen Semester III Sekolah Tinggi Ilmu Ekonomi Persada Bunda). Jurnal Pendidikan Ekonomi Akuntasi FKIP UIR. Vol.6, No.2: 90-103.

[4] Kementrian Pekerjaan Umum. 2007. Peraturan Menteri Pekerjaan Umum Nomor: 45/PRT/M/2007 Tentang Pedoman Teknis Pembangunan Gedung Negara. Jakarta.

[5] Kevin, dan Utomo, C. 2017. Analisis Highest and Best Use pada Lahan di Jalan tenggilis Timur 7 Surabaya. Jurnal Teknik Sipil ITS Vol.6, No.1 : D30-D34.

[6] Pemerintah Kota Surabaya. 2007. Peraturan Daerah Kota Surabaya Nomor 3 tahun 2007 Tentang Rencana Tata Ruang Wilayah Kota Surabaya. Surabaya. 
[7] Pemerintah Kota Surabaya. 2014. Rencana Detail Tata Ruang (RDTR) dan Peraturan Zonasi UP 1 Rungkut. Surabaya.

[8] Pemerintah Kota Surabaya. 2018. Peraturan Walikota Surabaya Nomor 30 tahun 2018 Tentang Perubahan Tarif Retribusi Tempat Parkir Khusus Parkir. Surabaya.

[9] Pemerintah Kota Surabaya. 2019. Lampiran III Keputusan Walikota Surabaya Nomor: 188.45/237/436.1.2/2019 Tentang Daftar Analisa Standar Belanja Pembangunan dan Pemeliharaan. Surabaya.

[10] Pemerintah Kota Surabaya. 2010. Peraturan Daerah Kota Surabaya Nomor 10 Tahun 2010 Tentang Pajak Bumi Dan Bangunan Perkotaan. Surabaya.

[11] Pemerintah Kota Surabaya. 2012. Peraturan Daerah Kota Surabaya Nomor 12 Tahun 2012 Tentang Retribusi Izin Mendirikan Bangunan. Surabaya.

[12] Timang, Y. F. 2017. Analisi HBU pada lahan kosong di Jalan Raya Diponegoro nomor 110-112 Surabaya. Tugas Akhir S1 Jurusan Teknik Sipil. 